\title{
Using Linguistic Features to Measure Presence in Computer-Mediated Communication
}

\author{
Adam D. I Kramer \\ Department of Psychology \\ University of Oregon \\ 1227 University of Oregon \\ Eugene, OR 97403 USA \\ adik@uoregon.edu
}

\author{
Lui Min Oh \\ DSO National Laboratories \\ 20 Science Park Drive \\ Singapore 118230 \\ keithoh@dso.org.sg
}

\author{
Susan R. Fussell \\ HCI Institute \\ Carnegie Mellon University \\ 5000 Forbes Avenue \\ Pittsburgh, PA 15206 USA \\ sfussell@cmu.edu
}

\begin{abstract}
We propose a method of measuring people's sense of presence in computer-mediated communication (CMC) systems) based on linguistic features of their dialogues. We create variations in presence by asking participants to collaborate on physical tasks in four CMC conditions. We then correlate self-reported feelings of presence with the use of specific linguistic features. Regression analyses show that $30 \%$ of the variance in self-reported presence can be accounted for by a small number of task-independent linguistic features. Even better prediction can be obtained when self-reported coordination is added to the regression equation. We conclude that linguistic measures of presence have value for studies of CMC.
\end{abstract}

\section{Author Keywords}

Presence, telepresence, experimentation, discourse analysis, computer-mediated communication, $\mathrm{CMC}$

\section{ACM Classification Keywords}

H5.3. Information interfaces and presentation (e.g., HCI): Group and Organizational Interfaces - collaborative computing, computer-supported cooperative work.

\section{INTRODUCTION}

The concept of "presence" has been defined as a sense of being in a remote or virtual environment [13]. Several different types of presence have been discussed in the literature, including personal presence, social presence, and object presence [e.g., 4, 13]. Here, we focus specifically on the feeling of being co-located with a set of distant objects.

Although presence is most often studied in research on virtual environments (VE), the concept is applicable to the study of computer-mediated communication (CMC). CMC

Permission to make digital or hard copies of all or part of this work for personal or classroom use is granted without fee provided that copies are not made or distributed for profit or commercial advantage and that copies bear this notice and the full citation on the first page. To copy otherwise, or republish, to post on servers or to redistribute to lists, requires prior specific permission and/or a fee.

CHI 2006, April 22-28, 2006, Montréal, Québec, Canada.

Copyright 2006 ACM 1-59593-178-3/06/0004..\$5.00. tools, such as audio conferencing, video conferencing, and instant messaging, transport users to greater or lesser degrees to the physical spaces of their remote collaborators [1]. While the importance of presence in users' experiences with CMC tools has been acknowledged for some time, the majority of studies do not include presence measures. Because presence is often (but not always) associated with better task performance in the VE literature, $\mathrm{CMC}$ research may benefit from a greater focus on presence.

One reason that $\mathrm{CMC}$ researchers rarely investigate presence may be that presence measures, such as questionnaires, physiological indices, and behavioral measures, can be onerous to collect. Although scales have been created to measure presence [e.g., 11, 12, 13], investigators may be reluctant to add large numbers of questions to their existing surveys. In addition, survey measures are retroactive and insensitive to changes in presence over the course of an interaction [5]. Physiological measures such as heart rate or skin conductance can provide sensitive, objective data in real-time [e.g., 8]. However, they require specialized equipment that may be unavailable or impractical in many research settings. Behavioral data such as startle responses are promising, but to date these measures have been applied primarily to VE technologies.

In this paper we present an alternative measure of presence based on linguistic features of people's communication. The logic behind this measure is closely aligned with that of behavioral presence measures: To the extent that people talk about a remote space in the same way they talk about local space, we can infer that they feel immersed in that remote space. Task-independent linguistic measures of presence are real-time and responsive to changes in behavior over the course of an interaction. A validated linguistic measure of presence could also be used to retroactively analyze presence in earlier CMC studies.

Technology shapes the way people talk about a physical environment and the entities and locations within that environment [e.g., 2]. For example, one study found that people using a video system with a live feed from a remote workspace referred to objects and locations in that workspace as if they were far away (e.g., that, there), whereas people given a tool that allowed them to draw over 
the live video feed referred to objects and locations as if they were nearby (e.g., this, here) [7]. We hypothesize that this linguistic difference reflects a psychological difference in how "present" people feel in the remote environment. To test this hypothesis, we examine the use of deixis, pronouns, and other task-independent language as a function of self-reported presence. To create variations in presence, we asked participants to collaborate on tasks using different media. In each case, a "Helper" located away from the workspace provided instructions to a "Worker" who was co-located with the workspace.

\section{METHOD}

\section{Design}

Thirty-eight pairs of undergraduates completed four robot assembly tasks under four media conditions: (a) audio only, (b) scene-oriented video conferencing: Helpers could view the output of a camera focused on the workspace; (c) sceneoriented video conferencing plus drawing tool: Helpers could draw on the video feed and the resulting video plus drawing appeared on a monitor in front of the worker's work space; and (d) face-to-face. The video plus drawing condition was included because it provides a way to interact, indirectly, with remote objects, and thereby potentially increase presence [10]. Tasks, trials, and media conditions were counterbalanced.

\section{Equipment}

A video camera, positioned 30 " to the back right of the Worker's task space, showed a 27 " by 31 " block of the work area. The video feed was distributed via a wireless local network to the Helper's PC. The drawing software was installed on a tablet PC with 12 " monitor running Windows XP. The software allowed Helpers to draw directly on top of the live video feed. The drawings and video were distributed by wireless network to the Worker's PC. Video images were 6" by 4.5 " on the Helper's PC and 6.5 " by 5 " on the Worker's PC. Drawings disappeared automatically after 3 seconds. A Sony WCS-999 wireless microphone system was used to record audio.

\section{Materials}

Tasks. The Robotix Vox Centurion robot kit (Figure 1) was used as the basis for four different ten-minute tasks (e.g., constructing the right arm).

Surveys. A pre-test survey collected basic demographic information. A post-task survey, administered after each task, asked questions about the success of each collaboration (e.g., "I am confident we completed this task correctly") on a 7-point scale ranging from 1 (strongly disagree) to 7 (strongly agree). In addition, a set of presence questions was adapted from the literature $[13,11]$. We adapted the wording of some questions to better fit our $\mathrm{CMC}$ environment. A final questionnaire, completed at the end of the experiment, contained questions about the participants' opinions of the relative value of the different media conditions.

\section{Participants and Procedure}

Within each pair, participants were randomly assigned to the Helper or Worker role. Participants were situated 11 feet apart with a barrier between them. They were given an overview of the study and filled out the pre-test. Helpers first constructed each part of the robot in order to familiarize themselves with

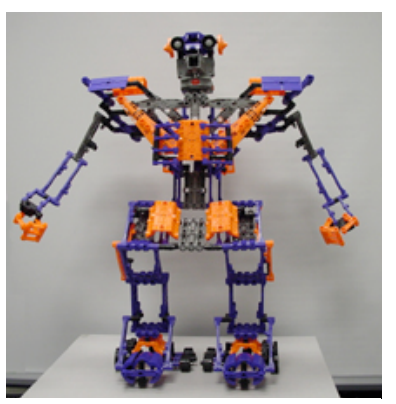

Figure 1. Robot used in the experiment. the tasks. Pairs then performed their four tasks. At the end of each task, they completed the post-task survey. After all tasks, they completed the final questionnaire. Sessions took approximately 60 minutes and participants received $\$ 15$.

\section{Processing of Conversational Data}

Conversations were transcribed and processed using Kramer et al's Text Analysis and Word Count software (TAWC) [6]. TAWC automatically identified instances of local deixis (e.g., this, here) and remote deixis (e.g., that, there). We also examined the use of several other word categories proposed by Pennebaker, Francis, and Booth [9] as task-independent linguistic measures (see Table 1).

\begin{tabular}{|l|l|}
\hline \multicolumn{1}{|c|}{ Word Category } & \multicolumn{1}{c|}{ Examples } \\
\hline Pronouns & \\
\hline I & I, my, me \\
\hline We & We, our, us \\
\hline You & You, you'll \\
\hline Other & He, she, them \\
\hline Positive emotions & Joy, love, good \\
\hline Negative emotions & Worthless, hate, tense \\
\hline Cognitive processes & Know, think, consider \\
\hline Social processes & Converse, share, friends \\
\hline Local deixis & This, these, here \\
\hline Remote deixis & That, those, there \\
\hline
\end{tabular}

Table 1. Linguistic categories used in the current study.

Counts for each linguistic variable were calculated by pair, role (Worker or Helper), and condition. To take into account differences in verbosity, all linguistic variables were analyzed as percents of total words. Because the focus of our investigation is on Helpers' perceptions of presence, only Helpers' words were analyzed.

\section{Processing of Survey Data}

Survey questions were subjected to factor analysis with Varimax rotation. The solution indicated two primary components. Factor 1 ( $25 \%$ of the variance) consisted of 9 questions measuring the helper's sense of presence in the remote workspace (see Table 2). Factor 2 (23\% of the variance) consisted of 11 questions pertaining to coordination between Helper and Worker. Presence and coordination scores were created for each participant by averaging across questions ( $\alpha=.93$ and .92 , respectively). 


\begin{tabular}{|l|c|}
\hline \multicolumn{1}{|c|}{ Presence Questions } & Loading \\
\hline I was able to actively look around the workspace & .87 \\
\hline I could examine objects closely when I wanted to & .83 \\
\hline I could see clearly what my partner was looking at & .75 \\
\hline $\begin{array}{l}\text { I felt like I was actually in the workspace rather } \\
\text { than observing it. }\end{array}$ & .73 \\
\hline I could identify objects easily & .67 \\
\hline $\begin{array}{l}\text { The objects in the workspace seemed very far away } \\
\text { to me. }\end{array}$ & -.58 \\
\hline $\begin{array}{l}\text { It was hard for me to tell what the worker was } \\
\text { doing }\end{array}$ & -.57 \\
\hline $\begin{array}{l}\text { It was easy for me to point out objects in the shared } \\
\text { workspace }\end{array}$ & .55 \\
\hline $\begin{array}{l}\text { I had difficulty seeing the objects I wanted to look } \\
\text { at. }\end{array}$ & -.50 \\
\hline
\end{tabular}

Table 2. Presence questions and factor loadings.

\section{RESULTS}

First, we examine the effects of media condition on task time, total words spoken, presence and coordination. Then, we present correlational and regression analyses associating the linguistic variables with our other dependent measures.

\begin{tabular}{|l|c|c|c|c|}
\hline & Audio & Video & $\begin{array}{c}\text { Video }+ \\
\text { Drawing }\end{array}$ & FtF \\
\hline Task time & $476.51^{\mathrm{a}}$ & $387.76^{\mathrm{b}}$ & $374.62^{\mathrm{b}}$ & $209.38^{\mathrm{c}}$ \\
\hline Total Words & $868.08^{\mathrm{a}, \mathrm{b}}$ & $722.05^{\mathrm{b}, \mathrm{c}}$ & $614.68^{\mathrm{c}}$ & $365.81^{\mathrm{d}}$ \\
\hline Presence & $2.44^{\mathrm{a}}$ & $4.59^{\mathrm{b}}$ & $4.91^{\mathrm{b}}$ & $6.26^{\mathrm{c}}$ \\
\hline Coordination & $4.40^{\mathrm{a}}$ & $5.39^{\mathrm{b}}$ & $5.74^{\mathrm{b}, \mathrm{c}}$ & $6.24^{\mathrm{c}}$ \\
\hline
\end{tabular}

Table 3. Task time in seconds, total words, Helpers' selfreported presence, and coordination, by media condition. Presence and coordination scores ranged from 1 (low) to 7 (high). Means with different superscripts differ at $p<.05$ or greater.

\section{Effects of media condition}

Data were analyzed using Mixed Models ANOVA with trial and condition as fixed factors and pair as a random factor. Consistent with prior research, we found significant effects of trial $(\mathrm{F}[3,70.44]=7.23, \mathrm{p}<.001)$ and condition $(\mathrm{F}[3,91.75]=42.19, \mathrm{p}<.001)$, as well as a marginal interaction between them $(\mathrm{F}[9,86.77]=1.95, \mathrm{p}=.06)$, on total task time. Similarly, there were main effects of trial ( $\mathrm{F}$ $[3,67.43]=6.81, \mathrm{p}<.001)$ and condition $(\mathrm{F}[3,97.52]=$ 63.19), but no interaction, on total words spoken per task.

As expected, the four media conditions gave rise to different levels of self-reported presence. Presence was highest in the face-to-face condition, lowest in the audioonly condition, and intermediate in the video conditions ( $F$ $[3,91.75]=42.19, p<.001)$. There was no effect of trial on presence but a significant interaction between trial and condition $(F[9,136.71]=2.78, p=.005)$ that indicated greater differences among conditions in later trials.

Media condition also affected self-reported coordination (F $[3,102.46]=37.80, p<.001)$. Coordination was best in the face-to-face condition, worst in the audio-only condition, and intermediate in the video conditions. Coordination improved over trials $(\mathrm{F}[3,55.50]=4.36, \mathrm{p}<.01)$ but there was no trial by condition interaction.

\section{Linguistic correlates of presence and coordination}

Table 4 shows the correlations between linguistic variables and other dependent measures. Presence scores were positively correlated with the use of we pronouns and negatively correlated with the use of you pronouns. This is consistent with the theory that greater presence makes remote collaborators feel as if they are together in a single environment. Presence scores were also highly correlated with the use of local deixis, suggesting that when people feel present in a remote environment, they talk about it in the same way they talk about their physical environment.

Presence scores were negatively correlated with mention of cognitive and social processes. While the former is consistent with the idea that lack of presence indicates a separation between self and environment, the explanation for the latter is currently unclear. As positive and negative emotion terms were uncorrelated with presence, we do not discuss them further.

Linguistic measures that are positively associated with presence are also positively associated with coordination and negatively associated with task time. Thus, presence is associated with positive team outcomes, although this study does not allow us to determine the direction of causality.

\begin{tabular}{|l|c|c|c|}
\hline & Time & Presence & Coord. \\
\hline Pronouns & $.23^{*}$ & $-.18^{*}$ & $-.15^{*}$ \\
\hline $\mathrm{I}$ & $.18^{*}$ & -.01 & -.03 \\
\hline $\mathrm{We}$ & $-.21 * *$ & $.26 *$ & $.17 *$ \\
\hline You & $.27 * *$ & $-.32 * *$ & $-.17^{*}$ \\
\hline Other & -.06 & -.03 & -.08 \\
\hline Positive emotions & .05 & .04 & .12 \\
\hline Negative emotions & -.07 & .13 & .07 \\
\hline Cognitive processes & $.32 * *$ & $-.22 * *$ & -.16 \\
\hline Social processes & $.21 *$ & $-.22 *$ & -.11 \\
\hline Local deixis & $-.33 * *$ & $.43^{* *}$ & $.36 * *$ \\
\hline Remote deixis & $-.19 *$ & .13 & .08 \\
\hline
\end{tabular}

Table 4. Correlation between linguistic variables and task time, presence, and coordination $(N=148) .{ }^{*} p<.05 ; * * p<$ .001 .

\section{Predicting presence scores from dialogue.}

To investigate the feasibility of using linguistic variables as a predictor of presence, we performed a regression predicting presence scores on the basis of the linguistic measures. This model was significant, and accounted for a third of the variance in presence scores $\left(\mathrm{R}^{2}=.33 ; \mathrm{F}[10\right.$, $137]=6.71, \mathrm{p}<.001)$. As shown in Table 5, higher levels of presence were associated with higher rates of local deixis, remote deixis, and we pronouns, and with lower rates of reference to cognitive processes. 


\begin{tabular}{|l|c|c|c|c|}
\hline & $\mathbf{B}$ & $\begin{array}{c}\text { Std. } \\
\text { Error }\end{array}$ & $\boldsymbol{\beta}$ & $\mathbf{t}$ \\
\hline (Constant) & 4.21 & .77 & & $5.45^{* *}$ \\
\hline Pronouns & & & & \\
\hline $\mathrm{I}$ & -1.54 & 2.05 & -.07 & -.76 \\
\hline $\mathrm{We}$ & 6.24 & 2.23 & .24 & $2.80^{*}$ \\
\hline You & -1.53 & 1.59 & -.12 & -.96 \\
\hline Other & -2.72 & 1.95 & -.11 & -1.39 \\
\hline $\begin{array}{l}\text { Cognitive } \\
\text { processes }\end{array}$ & -21.24 & 10.34 & -.19 & $-2.05^{*}$ \\
\hline $\begin{array}{l}\text { Social } \\
\text { processes }\end{array}$ & 6.67 & 9.81 & .08 & .68 \\
\hline Local deixis & 25.77 & 4.92 & .39 & $5.24^{* *}$ \\
\hline Remote deixis & 14.24 & 6.55 & .16 & $2.17^{*}$ \\
\hline
\end{tabular}

Table 5. Raw coefficients (B), standard errors, standardized coefficients $(\beta)$ and t-values from regressing linguistic variables onto presence scores. NOTE: ${ }^{*} \mathbf{p}<.05 ; *$ * $<.001$.

Helpers' presence and coordination scores were highly correlated $(\mathrm{r}=.74, \mathrm{p}<.001)$. To determine whether our linguistic features were simply predicting smooth coordination rather than presence, we performed a second regression in which we first entered coordination scores and then added the linguistic variables. The overall proportion of variance explained by this model increased $\left(\mathrm{R}^{2}=.63, \mathrm{~F}\right.$ $[11,136]=21.06, p<.001)$. However, adding the linguistic variables in the model produced a significant increase in predictive power, and individual $\mathrm{t}$ scores for local deixis $(\mathrm{t}$ $=2.92, \mathrm{p}<.005)$ and we pronouns $(\mathrm{t}=2.13, \mathrm{p}<.05)$ remained significant. Thus, the linguistic variables explain variance in self-reported presence beyond coordination scores alone.

\section{CONCLUSION}

Linguistic measures show promise for current and retrospective analysis of presence in CMC. In our study, a sizeable proportion of variance in self-reported presence was predicted by a small number of task-independent linguistic features, including pronouns, terms referring to cognitive processes, and local deixis. Although any single instance of a word such as here or there may not reflect presence, the percentage of such words during a conversation varies consistently with perceived presence. Prior research has shown that task-independent word categories vary reliably across tasks and media. We thus believe that our results are likely to generalize to other settings and tasks. In future work, we will use machine learning to automatically code presence from text and apply our techniques to our large corpus of dialogues from different media conditions.

\section{ACKNOWLEDGMENTS}

This material is based upon work supported by the National Science Foundation under Grant \#0208903. We thank Carmen Jackson, Jim Zheng and Gail Kusbit for their assistance.

\section{REFERENCES}

1. Buxton, W. (1992). Telepresence: Integrating shared task and personal spaces. Proc. Graphics Interface '92 (pp. 123-129).

2. Fussell, S. R., Setlock, L. D., \& Kraut, R. E. (2003). Effects of head-mounted and scene-oriented video systems on remote collaboration on physical tasks. Proc. CHI 2003 (pp. 513-520). NY: ACM Press.

3. Fussell, S. R., Setlock, L. D., Yang, J., Ou, J., Mauer, E. M., \& Kramer, A. (2004). Gestures over video streams to support remote collaboration on physical tasks. Human-Computer Interaction, 19, 273-309.

4. Heeter, C. (1992). Being there: The subjective experience of presence. Presence, 1, 262-271.

5. Insko, B. E. (2003). Measuring presence: Subjective, behavioral and physiological methods. In G. Riva, F. Davide, \& W. A. IJsselsteijn (Eds.), Being There: Concepts, effects and measurement of user presence in synthetic environments. Amsterdam: Ios Press.

6. Kramer, A. D. I., Fussell, S. R., \& Setlock, L. D. (2004). Text analysis as a tool for analyzing conversation in online support groups. CHI 2004 Late Breaking Results (pp. 1485-1488). NY: ACM Press.

7. Kramer, A. D. I., Fussell, S. R., \& Setlock, L. D. (2004, August). Deixis in face-to-face and computermediated conversations during collaborative physical tasks. Presented at the Annual meeting of the Society for Text and Discourse.

8. Meehan, M., Insko, B., Whitton, M., \& Brooks, F. P. Jr. (2002). Physiological measures of presence in stressful virtual environments. Proc. Siggraph 2002 (pp. 645-652). NY: ACM Press.

9. Pennebaker, J.W., Francis, M.E., \& Booth, R. J. (2001). Linguistic Inquiry and Word Count: LIWC $\left(2^{\text {nd }}\right.$ ed.). Mahwah, NJ: Lawrence Erlbaum Associates.

10. Stevens, B., Jerrams-Smith, J., Heathcote, D. \& Callear, D. (2002). Putting the virtual into reality: Assessing object-presence with projection-augmented models. Presence, 11, 79-92.

11. Usoh, M., Catena, E., Arman, S., \& Slater, M. (2000). Using presence questionnaires in reality. Presence, 9, 497-503.

12. Witmer, B. G., Jerome, C. J. \& Singer, M. J. (2005). The factor structure of the Presence Questionnaire. Presence, 14, 298-312.

13. Witmer, B. G., \& Singer, M. J. (1998). Measuring presence in virtual environments: A presence questionnaire. Presence, 7, 225-240. 